\title{
Impaired Hemorheology in Exacerbations of COPD
}

\author{
Erhan Ugurlu, ${ }_{1}$ Emine Kilic-Toprak, ${ }^{2}$ Ilknur Can, ${ }^{1}$ Ozgen Kilic-Erkek, ${ }^{2}$ \\ Goksel Altinisik, ${ }^{1}$ and Melek Bor-Kucukatay ${ }^{2}$ \\ ${ }^{1}$ Faculty of Medicine, Department of Pulmonology, Pamukkale University, Denizli, Turkey \\ ${ }^{2}$ Faculty of Medicine, Department of Physiology, Pamukkale University, Denizli, Turkey \\ Correspondence should be addressed to Emine Kilic-Toprak; pt_emine@yahoo.com
}

Received 6 May 2017; Revised 7 August 2017; Accepted 21 August 2017; Published 27 September 2017

Academic Editor: Franz Stanzel

Copyright (C) 2017 Erhan Ugurlu et al. This is an open access article distributed under the Creative Commons Attribution License, which permits unrestricted use, distribution, and reproduction in any medium, provided the original work is properly cited.

\begin{abstract}
Background. Chronic obstructive pulmonary disease (COPD) is characterized by progressive airflow limitation. Cardiovascularrelated comorbidities are established to contribute to morbidity and mortality especially during exacerbations. The aim of the current study was to determine alterations in hemorheology (erythrocyte aggregation, deformability) in newly diagnosed COPD patients and their response to medical treatment and to compare with values of COPD patients with exacerbations. Materials and Methods. The study comprised 13 COPD patients, 12 controls, and 16 COPD patients with exacerbations. The severity of COPD was determined according to Global Initiative for Chronic Obstructive Lung Disease guidelines. Red blood cell (RBC) deformability and aggregation were measured by an ektacytometer. Results. RBC deformability of COPD patients with exacerbations was decreased compared to the other groups. Erythrocyte aggregation and plasma fibrinogen of COPD patients determined during exacerbations were higher than control. Conclusion. Decreased RBC deformability and increased aggregation associated with exacerbations of COPD may serve as unfavorable mechanisms to worsen oxygenation and thus clinical symptoms of the patient. Treatment modalities that modify rheological parameters might be beneficial.
\end{abstract}

\section{Introduction}

Chronic obstructive pulmonary disease (COPD) is a common, preventable, and manageable disease process that is characterized by progressive persistent airflow restrictions and related to increased chronic inflammatory reaction of the airways and lungs against harmful gases and particles [1]. Exacerbations of COPD are defined as the worsening of symptoms such as increment of dyspnea, phlegm volume, and phlegm purulence, usually accompanied by hypoxia and hypercapnia $[2,3]$. The most common causes of COPD exacerbations are infections. Inflammation is an important component of the disease [4]. Macrophages and neutrophils play an important role in the inflammatory process [5]. On the other hand, RBC were proposed as biosensors for the stadium of COPD [6]. Nowadays, COPD treatment options include quitting smoking, pharmacological treatment (short-acting anticholinergic, short-acting beta ${ }_{2}$-agonist, long-acting anticholinergic, long-acting beta $_{2}$-agonist, and inhaled corticosteroids), and nonpharmacological treatment (pulmonary rehabilitation) [7-9]. Aim of pharmacological treatment is to improve the quality of life and exercise tolerance beside achieving the reduction of symptoms and attacks $[7,8]$. Inhaled corticosteroids specifically reduce the number of COPD exacerbations [10]. In COPD exacerbation first of all, it is important to identify the etiology. Viral and bacterial infections, air pollution, and environmental factors can initiate COPD exacerbation. Thus, antibiotics and oral steroids are choices of treatment [11].

Hemorheology is a branch of biorheology that focuses on blood and its interactions in both macro- and microcirculation under the influence of the applied constraints [12]. Erythrocyte deformability, red blood cell (RBC) aggregation, hematocrit (Hct), and blood viscosity are well-known components of hemorheology [12-14]. The flow properties of blood play significant roles in tissue perfusion. These properties are influenced by pathophysiological processes, including a variety of pulmonary diseases, thereby increasing the clinical relevance of blood rheology information [13, 15-17]. In COPD patients, RBC were shown to alter morphologically, 
like cytoskeleton changes, ultrastructural modifications, and reductions of glycophorin $\mathrm{A}$, band 3 , and $\mathrm{RBC}$ thiols $[7,18$, 19]. Rheological blood properties were demonstrated to progressively deteriorate as pulmonary insufficiency increases in patients with chronic bronchitis [18]. There are limited number of studies exploring hemorheological alterations in COPD [16, 20-22]. The results of these studies were obtained either from COPD patients at different stages of the illness and age $[18,20,22]$ or from patients receiving different types of therapy (medication, exercise) [16, 20, 23]. Additionally, different types of measurement techniques, some being rather old, were used in a variety of the studies mentioned above, which makes it difficult to compare the results [20, 21, 24]. Thus, we aimed to determine the possible alterations in RBC deformability and aggregation in newly diagnosed COPD patients and their response to medical treatment and to compare these parameters with values of COPD patients with exacerbations for the first time in the literature. The results of the current study are expected to contribute to the formation of alternative treatment options for COPD.

\section{Materials and Methods}

2.1. Subjects. Newly diagnosed patients with COPD as well as COPD patients with exacerbations according to the Global Initiative for Chronic Obstructive Lung Disease (GOLD) criteria at the Pulmonology Department of Pamukkale University were enrolled in the study. The severity of COPD was evaluated by the GOLD, the American Thoracic Society, and the European Respiratory Society. All subjects underwent respiratory function testing performed with the patient seated. Forced vital capacity (FVC), forced expiratory volume in the first second (FEV1), forced expiratory flow 25\% to $75 \%$ (FEF 25/75), and peak expiratory flow (PEF) were measured with a clinical spirometer. We considered the predicted percentage value of air exhaled during the first second of forced expiration (pred FEV1\%) and the Tiffeneau index (FEV1/FVC). In particular, pulmonary function test was evaluated in 13 newly diagnosed COPD patients before and after 1 month of medical treatment and in 16 COPD patients with exacerbations. The control group consisted of 12 subjects with comparable age and gender distribution. Among these subjects who had hypoxia (oxygen saturation $\leq 97 \%$ ) on a pulse oximeter reading applied via the finger, smokers and patients with other systemic diseases were excluded from the study. Patients with no obvious medical problem were included in newly diagnosed group. COPD exacerbation group consisted of severe and hospitalized patients. FEV1/FVC $<70 \%$ with an expected FEV1 $>80 \%$ indicates stage 1 (mild) of the disease process; $50 \%<\mathrm{FEV} 1<$ $80 \%$ indicates stage 2 disease (moderate); $30 \%<\mathrm{FEV} 1<50 \%$ indicates stage 3 disease (severe); and FEV1 $<30 \%$ indicates stage 4 disease (most severe) [1]. After obtaining pretreatment blood samples, patients were treated according to the stage of the illness. Posttreatment blood samples were taken after 1 month of treatment. Although 40 newly diagnosed patients were included in the beginning, 13 of them completed the study. Ethical approval was obtained from Pamukkale University Ethical Board on Human Experiments, with the approval number 60116787-020/35881. All participants gave their written informed consent to the study.

Treatment was in accordance with recently published guidelines. Combination of short-acting beta ${ }_{2}$ agonists and/ or short-acting anticholinergics was applied to stage I COPD patients, if necessary. Stage II patients were treated with long-acting anticholinergics for 1 month. COPD exacerbation group received antibiotics and oral or IV steroids.

2.2. Samples and Measurements. Venous blood samples of approximately $10 \mathrm{~mL}$ were drawn by venipuncture after 8 hours of fasting. Blood samples containing EDTA (1000/cs, $100 / \mathrm{cp}$ ) were appropriately transported to the physiology laboratory and hemorheological tests were performed within 3 hours in accordance with "new guidelines for hemorheological laboratory techniques" [25]. Hematological parameters as complete blood count were determined by an electronic hematology analyzer (Siemens ADVIA ${ }^{\circledR} 2120$ i System, Siemens Healthcare Diagnostics, Japan). Sodium citrated blood samples were analyzed for plasma fibrinogen concentration using a fully automated coagulometer [Beckman COULTER Acl top 700, instrumentation laboratory (USA)].

2.3. Erythrocyte Deformability Measurements. RBC deformability was determined at various fluid shear stresses by laser diffraction analysis using an ektacytometer (laser assisted optical rotational cell analyzer (LORCA), RR Mechatronics, Hoorn, Netherlands). The system has been described elsewhere in detail [26]. Briefly, a low Hct suspension of RBC in an isotonic viscous medium (4\% polyvinylpyrrolidone 360 solution; MW 360 kD; Sigma P 5288; St. Louis, MI) was sheared in a Couette system composed of a glass cup and a precisely fitting bob, with a gap of $0.3 \mathrm{~mm}$ between the cylinders. A laser beam was directed through the sheared sample, and the diffraction pattern produced by the deformed cells was analyzed by a microcomputer. On the basis of the geometry of the elliptical diffraction pattern, an elongation index (EI) was calculated as $\mathrm{EI}=(L-W) /(L+W)$, where $L$ and $W$ are the length and width of the diffraction pattern, respectively. EI values were determined for 9 shear stresses between 0.3 and $30 \mathrm{~Pa}$ and similar patterns of RBC deformability alterations were obtained between groups at all stress levels. All measurements were carried out at $37^{\circ} \mathrm{C}$. Subsequently, the shear stress for half-maximal deformation (SS1/2) was calculated using this nine-point data set for each measurement by employing a Lineweaver-Burk analysis as described elsewhere [27]. Briefly, the shear stress-EI curve was linearized by plotting the reciprocal of EI as a function of the reciprocal of shear stress: $1 / \mathrm{EI}=[(\mathrm{SS} 1 / 2 / \mathrm{EImax})(\mathrm{I} / \mathrm{SS})]+$ $1 /$ EImax, where SS is shear stress and EImax is the theoretical EI at infinite shear stress. The $x$-intercept of this line corresponds to the negative reciprocal value of shear stress causing half-maximal deformation (i.e., SS1/2); increased SS1/2 values indicate decreased RBC deformability.

2.4. Erythrocyte Aggregation Measurements. RBC aggregation was also determined by LORCA as described elsewhere [26]. The measurement is based on the detection of laser 
TABLE 1: Laboratory data of the groups.

\begin{tabular}{|c|c|c|c|c|c|c|}
\hline \multirow[b]{2}{*}{ Parameter } & \multirow[b]{2}{*}{$\begin{array}{l}\text { Control group } \\
\quad(n=12)\end{array}$} & \multicolumn{2}{|c|}{$\begin{array}{l}\text { Newly diagnosed } \\
\text { patient group }\end{array}$} & \multirow[b]{2}{*}{$\begin{array}{l}\text { Exacerbation group } \\
\qquad(n=16)\end{array}$} & \multirow[b]{2}{*}{$p_{1}$} & \multirow[b]{2}{*}{$p_{2}$} \\
\hline & & $\begin{array}{l}\text { Before } \\
\text { treatment } \\
(n=13)\end{array}$ & $\begin{array}{c}\text { After } \\
\text { treatment } \\
(n=13)\end{array}$ & & & \\
\hline $\mathrm{Hb}(\mathrm{g} / \mathrm{dl})$ & $15.24 \pm 1.75$ & $15.54 \pm 1.82$ & $15.28 \pm 1.51$ & $13.57 \pm 2.27^{\beta}$ & 0.052 & 0.033 \\
\hline Hct (\%) & $44.95 \pm 5.42$ & $47.45 \pm 6.17$ & $45.78 \pm 3.88$ & $40.93 \pm 6.35^{\#, \beta}$ & 0.013 & 0.045 \\
\hline $\mathrm{RBC}(\mathrm{m} / \mu \mathrm{L})$ & $5.06 \pm 0.61$ & $5.21 \pm 0.74$ & $5.05 \pm 0.55$ & $4.57 \pm 0.82$ & 0.149 & 0.106 \\
\hline MCV (fL) & $88.96 \pm 3.73$ & $91.41 \pm 6.57$ & $91.08 \pm 5.81$ & $90.13 \pm 6.65$ & 0.607 & 0.804 \\
\hline $\mathrm{MCH}(\mathrm{pg})$ & $30.17 \pm 0.97$ & $29.98 \pm 2.35$ & $30.34 \pm 2.07$ & $29.83 \pm 2.09$ & 0.905 & 0.753 \\
\hline $\mathrm{MCHC}(\mathrm{g} / \mathrm{dl})$ & $33.95 \pm 0.79$ & $32.80 \pm 1.07$ & $33.32 \pm 1.32$ & $33.13 \pm 1.41$ & 0.060 & 0.246 \\
\hline WBC (K/uL) & $7.41 \pm 1.53$ & $8.33 \pm 1.85$ & $8.66 \pm 1.80$ & $9.88 \pm 5.40$ & 0.228 & 0.231 \\
\hline Plt (K/uL) & $214.64 \pm 31.34$ & $242.69 \pm 49.77$ & $242.38 \pm 35.62$ & $274.19 \pm 154.62$ & 0.263 & 0.175 \\
\hline $\begin{array}{l}\text { Fibrinogen } \\
(\mathrm{mg} / \mathrm{dL})\end{array}$ & $321.18 \pm 115.24$ & $312 \pm 86.57$ & $292.27 \pm 74.51$ & $446.44 \pm 193.65^{*, \#, \beta}$ & 0.014 & 0.005 \\
\hline RDW (\%) & $12.81 \pm 0.77$ & $13.99 \pm 1.23$ & $13.93 \pm 1.34$ & $15.18 \pm 1.62^{*, \#}$ & 0.001 & 0.0001 \\
\hline
\end{tabular}

Values are expressed as means \pm SD (Hb: hemoglobin, Hct: hematocrit, RBC: red blood cell, MCV: mean corpuscular volume, MCH: mean corpuscular hemoglobin, MCHC: mean corpuscular hemoglobin concentration, WBC: white blood cell, Plt: platelet count, and RDW: red blood cell distribution width). $p_{1}$ : difference between the control group, before treatment of newly diagnosed COPD, and the exacerbation group; $p_{2}$ : difference between the control group, after treatment of newly diagnosed COPD, and the exacerbation group; ${ }^{*} p<0.05$ : difference from control, ${ }^{\#} p<0.05$ : difference from before treatment of COPD, and ${ }^{\beta} p<0.05$ : difference from after treatment of COPD.

backscattering from the sheared (disaggregated) and then unsheared (aggregating) blood, performed in a computerassisted system at $37^{\circ} \mathrm{C}$. Backscattering data were evaluated by the computer and the aggregation index (AI), aggregation half time $(t 1 / 2)$, and aggregation amplitude (AMP) were calculated on the basis that there is less light backscattered from aggregating red cells. Aggregation measurements were determined using RBC in autologous plasma adjusted to $40 \% \mathrm{Hct}$ and blood was fully oxygenated before the measurements.

2.5. Statistical Analyses. Continuous variables were expressed as mean \pm standard deviation (SD), median (minimum-maximum values), and categorical variables as number and percent. Shapiro-Wilk tests were used for testing normality. If parametric test conditions were satisfied, Analysis of Variance (ANOVA) was used for comparisons among groups. The post hoc Tukey test was used when the ANOVA determined a significant difference. If parametric test conditions were not satisfied, the Kruskal-Wallis Variance Analysis was used for comparisons among groups. The post hoc Mann-Whitney $U$ Test with Bonferroni Correction was used when the Kruskal-Wallis Variance Analysis determined a significant difference. For pairwise comparisons, if parametric test conditions were satisfied, Paired Samples $t$-test was used and if parametric test conditions were not satisfied, Wilcoxon signed rank test was used. All statistical analyses were done by SPSS 21.0. Power of the study was found to be over $95 \%$ with $95 \%$ confidence $(\alpha=0.05)$.

\section{Results}

Table 1 shows the demographic characteristics and laboratory data of the groups. The study enrolled 13 newly diagnosed
COPD patients ( 13 male) (mean age was $58.46 \pm 9.72$ years), 16 COPD patients with exacerbations (mean age was $67.75 \pm$ 8.29 years), and 12 age and sex matched healthy controls (12 male) (mean age was $54.16 \pm 11.4$ years) $(p>0.05)$. The patients had a $48.8 \pm 16.3$ pack-years smoking history. RDW of COPD patients during exacerbations was higher compared to control and pretreatment of newly diagnosed patients groups ( $p=0.0001$ and $p=0.039$, resp.), whereas fibrinogen level of this group was higher than all the other groups $(p<0.05)$. Additionally, $\mathrm{Hb}$ of COPD patients during exacerbations was less than posttreatment group $(p=0.05)$ and Hct of these patients were lower compared to both preand posttreatment groups ( $p=0.003$ and $p=0.05$, resp.). There was no other statistically significant alteration between the parameters demonstrated in Table $1(p>0.05)$.

Table 2 shows pulmonary function test results of the subjects. Mean baseline predicted value of FEV1, FEV1/FVC, PEF, and FEF 25/75 of control group were significantly higher than COPD patients $(p<0.05)$. The treatment applied in newly diagnosed patients did not cause statistically significant alterations in pulmonary function test results. FVC $(p=$ $0.001)$, FEV1, FEV1/FVC, and FEF 25/75 ( $p=0.0001)$ of COPD patients with exacerbations were lower than control group while PEF of these patients were decreased compared to both control group and COPD patients receiving treatment $(p=0.0001$ and $p=0.031$, resp.).

Erythrocyte deformability (i.e., the elongation index, EI) for the RBC of the experimental groups was measured at nine shear stresses between 0.3 and 30.0 pascal $(\mathrm{Pa})$ and shown in Table 3. RBC deformability of COPD patients with exacerbations measured at $0.53-30.00 \mathrm{~Pa}$ was decreased compared to control. On the other hand, EI of the same group measured at 0.30-9.49 $\mathrm{Pa}$ was lower than COPD patients receiving treatment $(p<0.05)$. 
TABLE 2: Pulmonary function test results of the subjects.

\begin{tabular}{|c|c|c|c|c|c|c|}
\hline \multirow[b]{2}{*}{ Pulmonary function test } & \multirow{2}{*}{$\begin{array}{l}\text { Control group } \\
\quad(n=12)\end{array}$} & \multicolumn{2}{|c|}{$\begin{array}{l}\text { Newly diagnosed } \\
\text { patient group }\end{array}$} & \multirow{2}{*}{$\begin{array}{l}\text { Exacerbation group } \\
\qquad(n=16)\end{array}$} & \multirow[b]{2}{*}{$p_{1}$} & \multirow[b]{2}{*}{$p_{2}$} \\
\hline & & $\begin{array}{l}\text { Before } \\
\text { treatment } \\
(n=13)\end{array}$ & $\begin{array}{c}\text { After } \\
\text { treatment } \\
(n=13)\end{array}$ & & & \\
\hline FVC (\%) & $97.67 \pm 14.07$ & $82.23 \pm 13.97$ & $88.77 \pm 16.10$ & $68.5 \pm 30.63^{*}$ & 0.005 & 0.006 \\
\hline $\mathrm{FEV}_{1}(\%)$ & $99.25 \pm 12.83$ & $66.69 \pm 13.83^{*}$ & $75.54 \pm 20.14^{*}$ & $64.36 \pm 16.10^{*}$ & 0.0001 & 0.0001 \\
\hline $\mathrm{FEV}_{1} / \mathrm{FVC}$ ratio & $82.58 \pm 6.04$ & $63.85 \pm 4.71^{*}$ & $64.46 \pm 8.66^{*}$ & $60.93 \pm 8.13^{*}$ & 0.0001 & 0.0001 \\
\hline $\operatorname{PEF}(\%)$ & $90.33 \pm 12.06$ & $64.69 \pm 16.12^{*}$ & $70.54 \pm 24.56^{*}$ & $46.88 \pm 29.38^{*, \beta}$ & 0.0001 & 0.0001 \\
\hline FEF 25-75 (\%) & $90.67 \pm 20.83$ & $35.38 \pm 9.40^{*}$ & $42.08 \pm 14.51^{*}$ & $25.38 \pm 16.20^{*}$ & 0.0001 & 0.0001 \\
\hline
\end{tabular}

Values are expressed as means $\pm \mathrm{SD}\left(\mathrm{FEV}_{1}\right.$ : forced expiratory volume in the first second, FVC: forced vital capacity, PEF: peak expiratory flow, and FEF 25/75: forced expiratory flow $25 \%$ to $75 \%$ ). $p_{1}$ : difference between the control group, before treatment of newly diagnosed COPD, and the exacerbation group; $p_{2}$ : difference between the control group, after treatment of newly diagnosed COPD, and the exacerbation group; ${ }^{*} p<0.05$ : difference from control, ${ }^{\#} p<0.05$ : difference from before treatment of COPD, and ${ }^{\beta} p<0.05$ : difference from after treatment of COPD. $p_{1}$ and $p_{2}$ are findings via ANOVA whereas other symbols are findings by comparison of two groups.

TABLE 3: The EI values of the groups at different shear stresses.

\begin{tabular}{|c|c|c|c|c|c|c|}
\hline \multirow[b]{2}{*}{$\begin{array}{l}\text { Shear stress } \\
(\mathrm{Pa})\end{array}$} & \multirow[b]{2}{*}{$\begin{array}{l}\text { Control group } \\
\quad(n=12)\end{array}$} & \multicolumn{2}{|c|}{$\begin{array}{l}\text { Newly diagnosed } \\
\text { patient group }\end{array}$} & \multirow[b]{2}{*}{$\begin{array}{l}\text { Exacerbation group } \\
\qquad(n=16)\end{array}$} & \multirow[b]{2}{*}{$p_{1}$} & \multirow[b]{2}{*}{$p_{2}$} \\
\hline & & $\begin{array}{l}\text { Before } \\
\text { treatment } \\
(n=13)\end{array}$ & $\begin{array}{l}\text { After } \\
\text { treatment } \\
(n=13)\end{array}$ & & & \\
\hline 0.30 & $0.06 \pm 0.03$ & $0.06 \pm 0.02$ & $0.05 \pm 0.02$ & $0.04 \pm 0.01^{\#}$ & 0.039 & 0.333 \\
\hline 0.53 & $0.12 \pm 0.05$ & $0.12 \pm 0.05$ & $0.08 \pm 0.04$ & $0.05 \pm 0.01^{*, \#}$ & 0.010 & 0.001 \\
\hline 0.95 & $0.21 \pm 0.08$ & $0.21 \pm 0.08$ & $0.17 \pm 0.057$ & $0.12 \pm 0.02^{*, \#}$ & 0.002 & 0.001 \\
\hline 1.69 & $0.33 \pm 0.10$ & $0.31 \pm 0.09$ & $0.26 \pm 0.07$ & $0.22 \pm 0.02^{*, \#}$ & 0.002 & 0.001 \\
\hline 3.00 & $0.41 \pm 0.07$ & $0.40 \pm 0.08$ & $0.36 \pm 0.06$ & $0.32 \pm 0.02^{*, \#}$ & 0.001 & 0.001 \\
\hline 5.33 & $0.49 \pm 0.05$ & $0.47 \pm 0.06$ & $0.45 \pm 0.06$ & $0.42 \pm 0.02^{*, \#}$ & 0.001 & 0.001 \\
\hline 9.49 & $0.55 \pm 0.04$ & $0.54 \pm 0.05$ & $0.51 \pm 0.05$ & $0.50 \pm 0.02^{*, \#}$ & 0.001 & 0.003 \\
\hline 16.87 & $0.60 \pm 0.04$ & $0.59 \pm 0.04$ & $0.57 \pm 0.04$ & $0.55 \pm 0.02^{*}$ & 0.006 & 0.002 \\
\hline 30.00 & $0.63 \pm 0.04$ & $0.63 \pm 0.04$ & $0.61 \pm 0.04$ & $0.59 \pm 0.02^{*}$ & 0.007 & 0.017 \\
\hline
\end{tabular}

Values are expressed as means \pm SD; EI: elongation index and Pa: pascal. $p_{1}$ : difference between the control group, before treatment of newly diagnosed COPD, and the exacerbation group; $p_{2}$ : difference between the control group, after treatment of newly diagnosed COPD, and the exacerbation group; ${ }^{*} p<0.05$ : difference from control, ${ }^{\#} p<0.05$ : difference from before treatment of COPD, and ${ }^{\beta} p<0.05$ : difference from after treatment of COPD. $p_{1}$ and $p_{2}$ are findings via ANOVA whereas other symbols are findings by comparison of two groups.

Table 4 demonstrates that EImax and SS1/2 of the exacerbation group were statistically significantly higher than the other groups $(p<0.05)$.

Erythrocyte aggregation parameters (AI and $\left.t_{1 / 2}\right)$ are demonstrated in Table 5. AI ( $p=0.0001)$ of COPD patients determined during exacerbations was higher whereas $t_{1 / 2}$ ( $p=0.001)$ was lower compared to control group. Increment of $\mathrm{AI}$ is in concordance with decrement of $t_{1 / 2}$ and indicates augmentation of RBC aggregation.

\section{Discussion}

COPD is a leading cause of mortality and morbidity with increasing prevalence worldwide $[28,29]$. It is a progressive condition characterized by a poorly reversible airflow limitation associated with an abnormal inflammatory response of the lung. There is evidence that, in different lung diseases, including COPD, blood cells may undergo distinct alterations. Erythrocytes are affected at different levels in COPD, including structural alterations [23, 30]. Furthermore, emerging themes in RBC biology support the new concept that erythrocytes are also signalling cells [31,32], with important roles in the regulation of biochemical interactions with other cells in (patho) physiology. Hypoxia is one of the prognostic factors in COPD [21]. Tissue oxygenation depends on three factors: (1) the functional integrity of the pulmonary, cardiac, and vascular system, (2) the quantity and quality of the hemoglobin molecule and binding of oxygen to hemoglobin, and (3) the flow characteristics of the blood (hemorheology) [33, 34]. Blood flow, RBC aggregation, and deformability are main components of hemorheology. In the microcirculation, $\mathrm{RBC}$ must collapse to pass through narrow capillaries; hence, RBC deformability and aggregation are major determinants of resistance to flow. The ability of the entire RBC to deform is critically important to perform its function of oxygen delivery and is also a determinant of cell 
TABLE 4: The EImax and SS1/2 values of the groups.

\begin{tabular}{|c|c|c|c|c|c|c|}
\hline & \multirow{2}{*}{$\begin{array}{l}\text { Control group } \\
\quad(n=12)\end{array}$} & \multicolumn{2}{|c|}{$\begin{array}{l}\text { Patient group } \\
\quad(n=13)\end{array}$} & \multirow{2}{*}{$\begin{array}{l}\text { Exacerbation group } \\
\qquad(n=16)\end{array}$} & \multirow{2}{*}{$p_{1}$} & \multirow{2}{*}{$p_{2}$} \\
\hline & & Before treatment & After treatment & & & \\
\hline EImax & $0.64 \pm 0.21$ & $0.68 \pm 0.24$ & $0.66 \pm 0.37$ & $0.83 \pm 0.15^{*, \#, \beta}$ & 0.001 & 0.0001 \\
\hline $\mathrm{SS} 1 / 2$ & $2.06 \pm 1.29$ & $3.16 \pm 3.65$ & $4.64 \pm 7,92$ & $6.17 \pm 3.3^{*, \#, \beta}$ & 0.0001 & 0.0001 \\
\hline
\end{tabular}

Values are expressed as means \pm SD; EImax: theoretical EI at infinite shear stress and SS1/2: shear stress at half-maximal deformation. $p_{1}$ : difference between the control group, before treatment of newly diagnosed COPD, and the exacerbation group; $p_{2}$ : difference between the control group, after treatment of newly diagnosed COPD, and the exacerbation group; ${ }^{*} p<0.05$ : difference from control, ${ }^{*} p<0.05$ : difference from before treatment of COPD, and ${ }^{\beta} p<0.05$ : difference from after treatment of COPD. $p_{1}$ and $p_{2}$ are findings via ANOVA whereas other symbols are findings by comparison of two groups.

TABLE 5: The RBC aggregation measurements of the groups.

\begin{tabular}{|c|c|c|c|c|c|c|}
\hline & \multirow[b]{2}{*}{$\begin{array}{l}\text { Control group } \\
\quad(n=12)\end{array}$} & \multicolumn{2}{|c|}{ Newly diagnosed patient group } & \multirow[b]{2}{*}{$\begin{array}{l}\text { Exacerbation group } \\
\qquad(n=16)\end{array}$} & \multirow[b]{2}{*}{$p_{1}$} & \multirow[b]{2}{*}{$p_{2}$} \\
\hline & & $\begin{array}{l}\text { Before treatment } \\
\qquad(n=13)\end{array}$ & $\begin{array}{l}\text { After treatment } \\
\quad(n=13)\end{array}$ & & & \\
\hline $\operatorname{AMP}(\mathrm{au})$ & $25.0 \pm 2.91$ & $25.1 \pm 3.90$ & $24.65 \pm 3.18$ & $20.77 \pm 3.59^{*, \#, \beta}$ & 0.002 & 0.002 \\
\hline $\mathrm{AI}(\%)$ & $68.15 \pm 5.90$ & $72.33 \pm 6.16$ & $73.16 \pm 8.17$ & $79.96 \pm 3.61^{*}$ & 0.0001 & 0.007 \\
\hline$t 1 / 2(\mathrm{sn})$ & $1.79 \pm 0.55$ & $1.45 \pm 0.55$ & $1.39 \pm 0.68$ & $1.01 \pm 0.37^{*}$ & 0.001 & 0.003 \\
\hline
\end{tabular}

Values are expressed as means $\pm \mathrm{SD}$; AMP: amplitude of aggregation; AI: aggregation index; $t 1 / 2$ : aggregation half time. $p_{1}$ : difference between the control group, before treatment of newly diagnosed COPD, and the exacerbation group; $p_{2}$ : difference between the control group, after treatment of newly diagnosed COPD, and the exacerbation group; ${ }^{*} p<0.05$ : difference from control, ${ }^{\#} p<0.05$ : difference from before treatment of COPD, and ${ }^{\beta} p<0.05$ : difference from after treatment of COPD.

survival time in the circulation $[35,36]$. RBC aggregation is a reversible process meaning a temporary linear or branched aggregate formation of the erythrocytes under critically low shear stress conditions. The physiological importance of erythrocyte aggregation which is the reversible adhesion of adjacent erythrocytes in circulation is its tendency to increase the blood viscosity in low shear flow and to disturb the passage in capillary circulation $[37,38]$.

Current study demonstrates hemorheological parameters (i.e., RBC deformability and aggregation) in newly diagnosed stage 1-2 COPD patients and the alterations in these parameters in response to one-month medical treatment and compares these parameters with values of COPD patients during acute exacerbations. RDW of COPD patients during exacerbations was increased, and $\mathrm{Hb}$ and $\mathrm{Hct}$ decreased as expected $[39,40]$. No statistically significant alteration was observed in deformability of the RBC of the newly diagnosed experimental groups measured at nine shear stresses between 0.3 and $30.0 \mathrm{~Pa}$ as well as Elmax and SS1/2 values. Similar to our results, Karul et al. found no difference in osmotic fragility of stable COPD patients compared to controls [21]. On the other hand, Coppola et al. measured erythrocyte filterability in 15 COPD patients of 67-79 years old and found it decreased [20]. Santini et al. demonstrated an increase in membrane rigidity in erythrocytes of COPD patients with respect to controls. According to the authors, this increase in red cell rigidity might be due to enhanced sphingomyelin values [30]. Index of RBC deformability was also found to be decreased in chronic cor pulmonale decompensation [18, 22]. The disparity in RBC deformability results seems to be due to the technique used, age of the patients, severity of the disease, and the presence of complications. LORCA (laser assisted optical rotational cell analyzer) which is an up-to-date device to measure RBC deformability and aggregation with a good repetition of consecutive measurements was used in our study. Results of the current study demonstrate for the first time in the literature that RBC deformability of COPD patients with exacerbations is lower than both healthy subjects (at 0.53-30.00 Pa) and newly diagnosed COPD patients receiving treatment (at $0.30-9.49 \mathrm{~Pa}$ ). It was mentioned before that impaired RBC deformability leads to increased SS1/2 values. The shear stress level of normal pulmonary circulation was demonstrated to be around $2-3 \mathrm{~Pa}$ [41]. This information increases the importance of the reduced RBC deformability determined at 1.69 and $3 \mathrm{~Pa}$ in COPD exacerbations, herein. When EImax and SS1/2 values were evaluated, erythrocyte deformability of the COPD patients with exacerbations was also found to be lower compared to COPD patients before treatment. These reports support the suggestion that presentation and comparison of data via this approach may provide a more comprehensive view of RBC stress-deformation behavior compared to shear stress-EI curves since it utilizes the entire range of shear stress [27]. The relations between pressure and blood flow become more complex in the microcirculation as the vessel diameter approaches average RBC size [42]. In addition to the existing lung pathology, decreased RBC deformability in COPD patients during exacerbations may serve as an unfavorable factor to worsen the clinical condition of the patient by further disrupting tissue oxygenation.

Another hemorheological parameter measured in our study is the RBC aggregation. The aggregation index (AI) and aggregation half time $(t 1 / 2)$ of newly diagnosed COPD patients were not different from healthy subjects. One month of appropriate treatment did not cause any statistically significant alteration in the aggregation parameters of the patients nor the FVC, PEF, and $\mathrm{FEV}_{1} / \mathrm{FVC}$ ratio. AI of COPD patients 
with exacerbations was higher whereas $t_{1 / 2}$ was lower than healthy subjects. Increment of AI is in concordance with decrement of $t_{1 / 2}$ and indicates augmentation of RBC aggregation. Similarly, Osipova et al. evaluated hemorheological properties by spontaneous aggregation of erythrocytes and observed a concurrently higher aggregation of erythrocytes in patients with COPD. The rheological blood properties worsened as hypertension of the small blood-circulation circle was increasing [43]. Index of RBC aggregation was found to increase in chronic cor pulmonale decompensation $[18,22]$. Functional disturbances of erythrocytes in chronic bronchitis patients were shown to aggravate the course of the disease and need correction with membrane-stabilizing and membrane-repairing drugs $[15,18]$. Plasma fibrinogen level is known as one of the most important determinants of RBC aggregation. The tendency to aggregate increases as fibrinogen concentration rises [34]. Thus, increased fibrinogen level observed in our COPD exacerbation group may provide an explanation for the augmentation of RBC aggregation in this group. Additionally, although not determined in our study, increases in plasma levels of inflammatory cytokines IL-6 and IL- 8 were demonstrated in acute exacerbations of COPD [44] which may also alter RBC aggregation. It is also worth noting here that, in addition to decreased RBC deformability, increment of erythrocyte aggregation in COPD patients with exacerbation may also further play a role in diminishing circulation.

Oxidative stress represents one of the key mechanisms in the development of COPD [45]. Numerous studies have shown that oxidative stress is increased in lungs and systemic circulation of patients with COPD [46-50]. Markers of oxidative stress were found to increase even further during exacerbations of COPD [51] and in patients with very severe form of this disease [52]. Some studies have also demonstrated a marked decrease in plasma antioxidant capacity of COPD patients, while other studies have shown opposite findings [53]. RBC mechanical properties (i.e., erythrocyte deformability and aggregation) are known to be altered in response to oxidative stress $[54,55]$. Although possible changes in oxidative stress parameters were not investigated in our study, due to the above information, it can be speculated here that impaired hemorheology herein may at least partly be due to increased oxidative stress in these patients.

\section{Conclusion}

In overview, the results of the current study indicate that exacerbations of COPD are characterized by significant hemorheological abnormalities known to adversely affect blood flow. The decrement observed in RBC deformability and the increment shown in erythrocyte aggregation during exacerbations might complement other pathophysiologic mechanisms, leading to worsening of oxygenation and thus clinical symptoms. The mechanisms of the hemorheological alterations could not be clarified. Oxidative stress and inflammation may be involved. Therapeutic approaches including antioxidants for normalizing hemorheological parameters during exacerbations of COPD may also be recommended. However, whether therapies to decrease RBC aggregation and enhance deformability directly and specifically can be developed and whether such therapies will relieve the patient's symptoms remain an area of active investigation. Further research with a larger number of patients to explain the mechanisms of hemorheological alterations may be necessary.

\section{Disclosure}

The funding organizations had no role in the design and conduct of the study; the collection, management, analysis, and interpretation of the data; the preparation, review, or approval of the manuscript; or the decision to submit the manuscript for publication. The abstract of this study was presented as an oral presentation in the 42nd National Physiology Congress (Düzce University, Konuralp Campus, Turkey, 5-8 September 2016) by Emine Kilic-Toprak and published in a supplement of the Acta Physiologica Journal (Sep 2016, vol 218 S709, p. 12).

\section{Conflicts of Interest}

The authors declare that they have no conflicts of interest.

\section{Authors' Contributions}

Erhan Ugurlu contributed to the study design and data collection, performed the statistical analysis, interpreted the data, drafted the manuscript, reviewed the radiology, assessed the severity of disease, and assisted with manuscript composition. Emine Kilic-Toprak contributed to the study design and data collection, performed the statistical analysis, interpreted the data, and drafted the manuscript. Ilknur Can contributed to the study design and data collection, performed the statistical analysis, interpreted the data, and drafted the manuscript. Ozgen Kilic-Erkek contributed to the study design, performed the data collection, and helped to draft the manuscript. Göksel Altinisik contributed to the study design, data acquisition, and reading and approving the final manuscript. Melek Bor-Kucukatay contributed to study design and writing the manuscript and revision of manuscript for important intellectual content and reading and approving the final manuscript.

\section{References}

[1] J. Vestbo, S. S. Hurd, A. G. Agustí et al., "Global strategy for the diagnosis, management, and prevention of chronic obstructive pulmonary disease," American Journal of Respiratory and Critical Care Medicine, vol. 187, no. 4, pp. 347-365, 2013.

[2] E. Merinopoulou, M. Raluy-Callado, S. Ramagopalan, S. Maclachlan, and J. M. Khalid, "COPD exacerbations by disease severity in England," International Journal of COPD, vol. 11, no. 1, pp. 697-709, 2016.

[3] Y. Duan, M. Zhou, J. Xiao et al., "Prediction of key genes and miRNAs responsible for loss of muscle force in patients during an acute exacerbation of chronic obstructive pulmonary disease," International Journal of Molecular Medicine, vol. 38, no. 5, pp. 1450-1462, 2016. 
[4] S. Santos, A. Marin, J. Serra-Batlles et al., "Treatment of patients with COPD and recurrent exacerbations: the role of infection and inflammation," International Journal of COPD, vol. 11, no. 1 , pp. 515-525, 2016.

[5] M. Decramer, W. Janssens, and M. Miravitlles, "Chronic obstructive pulmonary disease," The Lancet, vol. 379, no. 9823, pp. 1341-1351, 2012.

[6] G. Lucantoni, D. Pietraforte, P. Matarrese et al., "The red blood cell as a biosensor for monitoring oxidative imbalance in chronic obstructive pulmonary disease: An ex vivo and in vitro study," Antioxidants and Redox Signaling, vol. 8, no. 7-8, pp. 1171$1182,2006$.

[7] B. Han, W. J. Poppinga, H. Zuo et al., "The novel compound Sul-121 inhibits airway inflammation and hyperresponsiveness in experimental models of chronic obstructive pulmonary disease," Scientific Reports, vol. 6, Article ID 26928, 2016.

[8] M. Osthoffa, C. Jenkins, and J. D. Leuppi, "Chronic obstructive pulmonary disease-A treatable disease," Swiss Medical Weekly, vol. 143, Article ID w13777, 2013.

[9] K. J. Davis, S. H. Landis, Y.-M. Oh et al., "Continuing to confront COPD international physician survey: physician knowledge and application of COPD management guidelines in 12 countries," International Journal of COPD, vol. 9, pp. 597-611, 2014.

[10] J. Vestbo, R. Pauwels, J. A. Anderson, P. Jones, and P. Calverley, "Early onset of effect of salmeterol and fluticasone propionate in chronic obstructive pulmonary disease," Thorax, vol. 60, no. 4, pp. 301-304, 2005.

[11] Global Strategy for the Diagnosis, Management and Prevention of COPD: Global Initiative for Chronic Obstructive Lung Disease (GOLD) 2017, http://goldcopd.org/gold-2017-globalstrategy-diagnosis-management-prevention-copd.

[12] A. V. Muravyov, S. V. Draygin, N. N. Eremin, and A. A. Muravyov, "The microrheological behavior of young and old red blood cells in athletes," Clinical Hemorheology and Microcirculation, vol. 26, pp. 183-188, 2002.

[13] M. J. Simmonds, H. J. Meiselman, and O. K. Baskurt, "Blood rheology and aging," Journal of Geriatric Cardiology, vol. 10, no. 3, pp. 291-301, 2013.

[14] I. A. Tikhomirova, A. O. Oslyakova, and S. G. Mikhailova, "Microcirculation and blood rheology in patients with cerebrovascular disorders," Clinical Hemorheology and Microcirculation, vol. 49, pp. 295-305, 2011.

[15] E. A. Stepovaya, V. V. Novitskiǔ, N. V. Ryazantseva, V. E. Gol'dberg, and etal., "Chronic bronchitis: participation of red cells in the pathologic process," Klinicheskaia Meditsina, vol. 82, pp. 53-56, 2004.

[16] B. Ahmad, N. Ferrari, G. Montiel et al., "Influence of a moderate physical activity intervention on red cell deformability in patients suffering from chronic obstructive pulmonary disease (COPD)," Wiener Medizinische Wochenschrift, vol. 163, no. 1314, pp. 334-339, 2013.

[17] E. Ugurlu, E. Kilic-Toprak, G. Altinisik, and etal., "Increased erythrocyte aggregation and oxidative stress in patients with idiopathic interstitial pneumonia," Sarcoidosis, Vasculitis and Diffuse Lung Diseases, vol. 33, pp. 308-316, 2016.

[18] I. P. Danilov and A. E. Makarevich, "Mechanisms of blood rheological disorders and their role in the progression of chronic obstructive bronchitis," Terapevticheskii Arkhiv, vol. 57, no. 3, pp. 19-22, 1985.

[19] J. Zhou, D. Wu, Y. Zhu, D. Ding, and F. Peng, "Hemorrheological status in patients with silicosis and its clinical significance,"
Zhonghua Yu Fang Yi Xue Za Zhi, vol. 33, no. 6, pp. 348-350, 1999.

[20] L. Coppola, G. Verrazzo, G. Esposito et al., "Hemorheological and cardiovascular effects of exercise training in the rehabilitation of elderly patients with chronic obstructive pulmonary disease," Archives of Gerontology and Geriatrics, vol. 28, no. 1, pp. 1-8, 1999.

[21] A. B. Karul, F. Karadag, D. Kozaci, and C. Altun, "Erythrocyte fragility is not altered in stablechronic obstructive pulmonary diseasewith normal arterial pH," Clinical Hemorheology and Microcirculation, vol. 28, pp. 107-112, 2003.

[22] O. N. Verbitskii, I. V. Buturov, and T. Iu. Purkh, "hemodynamics, blood gas composition and viscosity in patients with chronic obstructive bronchitis complicated by chronic cor pulmonale," Probl Tuberk Bolezn Legk, vol. 7, pp. 42-45, 2004.

[23] E. Straface, P. Matarrese, L. Gambardella et al., "N-acetylcysteine counteracts erythrocyte alterations occurring in chronic obstructive pulmonary disease," Biochemical and Biophysical Research Communications, vol. 279, no. 2, pp. 552-556, 2000.

[24] M. Piagnerelli, K. Zouaoui Boudjeltia, D. Brohee et al., "Assessment of erythrocyte shape by flow cytometry techniques," Journal of Clinical Pathology, vol. 60, no. 5, pp. 549-554, 2007.

[25] O. K. Baskurt, M. Boynard, G. C. Cokelet, and etal., "International expert panel for standardization of hemorheological methods. New guidelines for hemorheological laboratory techniques," Clinical Hemorheology and Microcirculation, vol. 42, pp. 75-97, 2009.

[26] M. R. Hardeman, P. Goedhart, and S. Shin, "Methods in hemorheology," in Handbook of Hemorheology and Hemodynamics, O. K. Baskurt, M. R. Hardeman, M. R. Rampling, and H. J. Meiselman, Eds., pp. 242-266, IOS Press, Amsterdam, The Netherlands, 2007.

[27] O. K. Baskurt and H. J. Meiselman, "Analyzing shear stresselongation index curves: comparison of two approaches to simplify data presentation," Clinical Hemorheology and Microcirculation, vol. 31, pp. 23-30, 2004.

[28] A. D. Lopez, K. Shibuya, C. Rao et al., "Chronic obstructive pulmonary disease: current burden and future projections," European Respiratory Journal, vol. 27, no. 2, pp. 397-412, 2006.

[29] Global strategy for the diagnosis, management, and prevention of COPD: Global Initiative for Chronic Obstructive Lung Disease (GOLD) 2014, http://www.goldcopd.org/.

[30] M. T. Santini, E. Straface, A. Cipri, M. Peverini, M. Santulli, and W. Malorni, "Structural alterations in erythrocytes from patients with chronic obstructive pulmonary disease," Haemostasis, vol. 27, no. 4, pp. 201-210, 1997.

[31] L. Yang, D. A. Andrews, and P. S. Low, "Lysophosphatidic acid opens a Ca ${ }^{++}$channel in human erythrocytes," Blood, vol. 95, no. 7, pp. 2420-2425, 2000.

[32] J. R. Pawloski, D. T. Hes, and J. S. Stamler, "Export by red blood cells of nitric oxide bioactivity," Nature, vol. 409, no. 6820, pp. 622-626, 2001.

[33] O. K. Baskurt and H. J. Meiselman, "Blood rheology and hemodynamics," Seminars in Thrombosis and Hemostasis, vol. 29, no. 5, pp. 435-450, 2003.

[34] O. K. Baskurt, "Pathophysiological significance of blood rheology," Turkish Journal of Medical Sciences, vol. 33, pp. 347-355, 2003.

[35] Z. Y. Wen, L. C. Song, Z. Y. Yan et al., "An animal model to study erythrocyte, senescence with a narrow time window of 
erythrocyte production: Alterations in osmotic fragility and deformability of erythrocytes during their life span," Clinical Hemorheology and Microcirculation, vol. 19, pp. 299-306, 1998.

[36] G. Cicco and A. Pirrelli, "Red blood cell (RBC) deformability, RBC aggregability and tissue oxygenation in hypertension," Clinical Hemorheology and Microcirculation, vol. 21, no. 3-4, pp. 169-177, 1999.

[37] B. Hiebl, C. Mrowietz, S. Lee et al., "Influence of rheological parameters on the velocity of erythrocytes passing nailfold capillaries in humans," Microvascular Research, vol. 48, pp. 129139, 2011.

[38] O. K. Baskurt and H. J. Meiselman, "Erythrocyte aggregation: basic aspects and clinical importance," Clinical Hemorheology and Microcirculation, vol. 53, pp. 23-27, 2013.

[39] R. Farah, R. Ibrahim, M. Nassar, D. Najib, Y. Zivony, and E. Eshel, "Neutrophil lymphocyte ratio better addition to CRP than CD64 index as marker for infection in COPD," Panminerva Med, vol. 9, 2017.

[40] E. Günay, S. Sarinç Ulaşli, O. Akar et al., "Neutrophil-tolymphocyte ratio in chronic obstructive pulmonary disease: a retrospective study," Inflammation, vol. 37, no. 2, pp. 374-380, 2014.

[41] M. Schäfer, V. O. Kheyfets, J. D. Schroeder et al., "Main pulmonary arterial wall shear stress correlates with invasive hemodynamics and stiffness in pulmonary hypertension," Pulmonary Circulation, vol. 6, no. 1, pp. 37-45, 2016.

[42] H. H. Lipowsky, "Microvascular rheology and hemodynamics," Microcirculation, vol. 12, no. 1, pp. 5-15, 2005.

[43] O. L. Osipova, V. E. Perleı̆, G. P. Orlova, A. I. U. Gichkin, and N. G. Iakovleva, "Blood rheological properties and their interrelation with pulmonary hypertension in patients with chronic dust bronchitis," in Kliniceskaja Laboratornaja Diagnostika, vol. 8, pp. 30-31, 2004.

[44] V. Austin, P. J. Crack, S. Bozinovski, A. A. Miller, and R. Vlahos, "COPD and stroke: are systemic inflammation and oxidative stress the missing links?” Clinical Science, vol. 130, no. 13, pp. 1039-1050, 2016.

[45] J. E. Repine, A. Bast, and I. Lankhorst, "Oxidative stress in chronic obstructive pulmonary disease," American Journal of Respiratory and Critical Care Medicine, vol. 156, no. 2 I, pp. 341357, 1997.

[46] P. A. Kirkham and P. J. Barnes, "Oxidative stress in COPD," Chest, vol. 144, no. 1, pp. 266-273, 2013.

[47] U. Can, F. H. Yerlikaya, and S. Yosunkaya, "Role of oxidative stress and serum lipid levels in stable chronic obstructive pulmonary disease," Journal of the Chinese Medical Association, vol. 78, no. 12, pp. 702-708, 2015.

[48] R. C. J. Langen, S. H. Korn, and E. F. M. Wouters, "ROS in the local and systemic pathogenesis of COPD," Free Radical Biology and Medicine, vol. 35, no. 3, pp. 226-235, 2003.

[49] W. MacNee, "Pulmonary and systemic oxidant/antioxidant imbalance in chronic obstructive pulmonary disease," in Proceedings of the American Thoracic Society, vol. 2, pp. 50-60, Scotland, UK, 2005.

[50] W. Domej, K. Oettl, and W. Renner, "Oxidative stress and free radicals in COPD-implications and relevance for treatment," International Journal of Chronic Obstructive Pulmonary Disease, vol. 9, pp. 1207-1224, 2014.

[51] P. N. R. Dekhuijzen, K. K. H. Aben, I. Dekker et al., "Increased exhalation of hydrogen peroxide in patients with stable and unstable chronic obstructive pulmonary disease," The American
Journal of Respiratory and Critical Care Medicine, vol. 154, no. 3, pp. 813-816, 1996.

[52] K. Kostikas, G. Papatheodorou, K. Psathakis, P. Panagou, and S. Loukides, "Oxidative stress in expired breath condensate of patients with COPD," Chest, vol. 124, no. 4, pp. 1373-1380, 2003.

[53] J. C. Mak, "Pathogenesis of COPD. Part II. Oxidativeantioxidative imbalance," International Journal of Tuberculosis and Lung Disease, vol. 12, pp. 368-374, 2008.

[54] O. K. Baskurt, A. Temiz, and H. J. Meiselman, "Effect of superoxide anions on red blood cell rheologic properties," Free Radical Biology and Medicine, vol. 24, no. 1, pp. 102-110, 1998.

[55] O. K. Baskurt and H. J. Meiselman, "Activated polymorphonuclear leukocytes affect red blood cell aggregability," Journal of Leukocyte Biology, vol. 63, no. 1, pp. 89-93, 1998. 


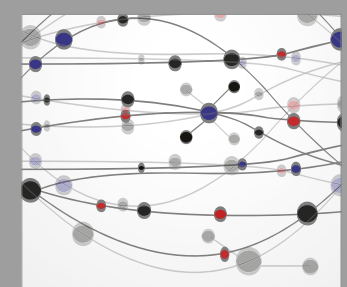

The Scientific World Journal
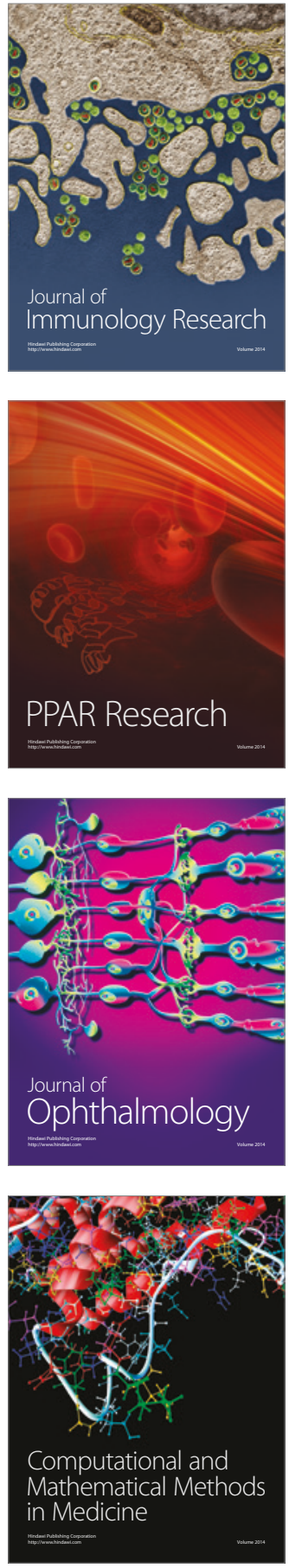

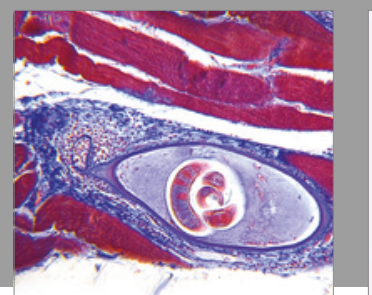

Gastroenterology Research and Practice
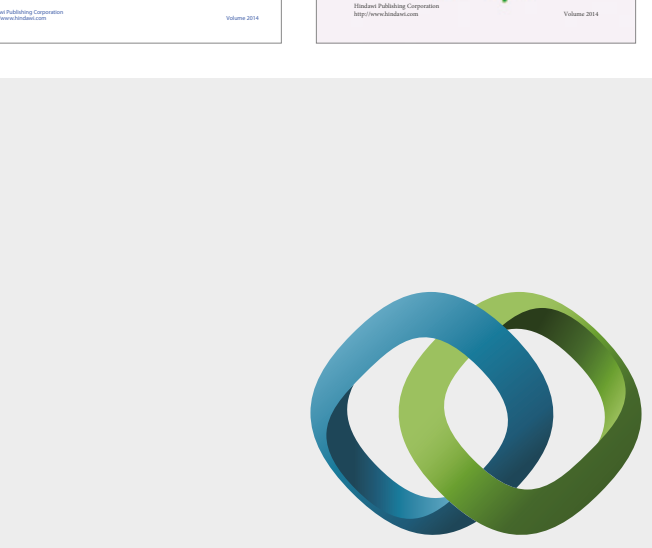

\section{Hindawi}

Submit your manuscripts at

https://www.hindawi.com
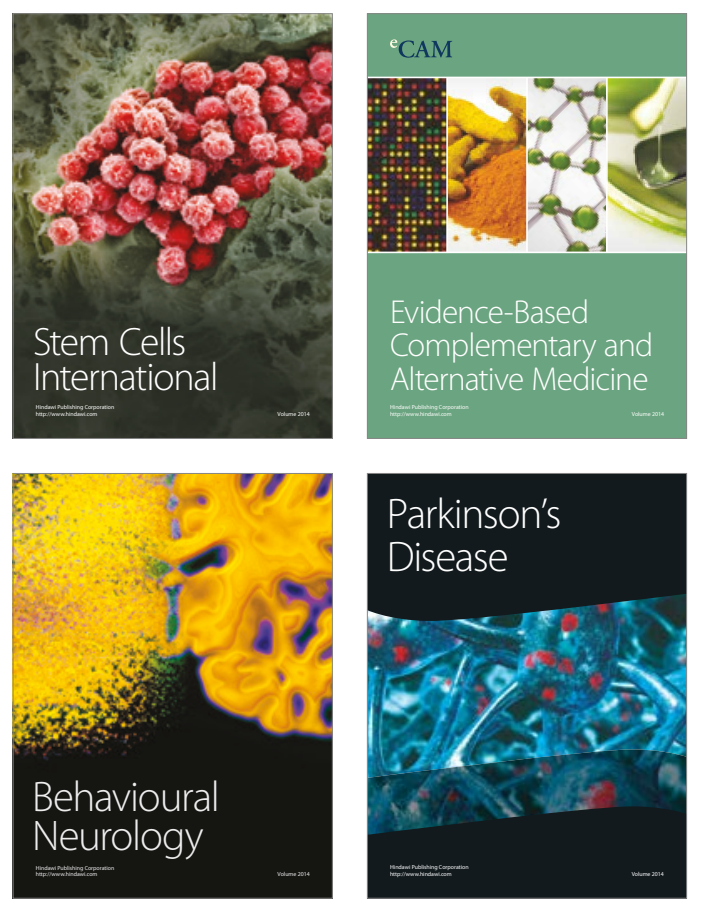
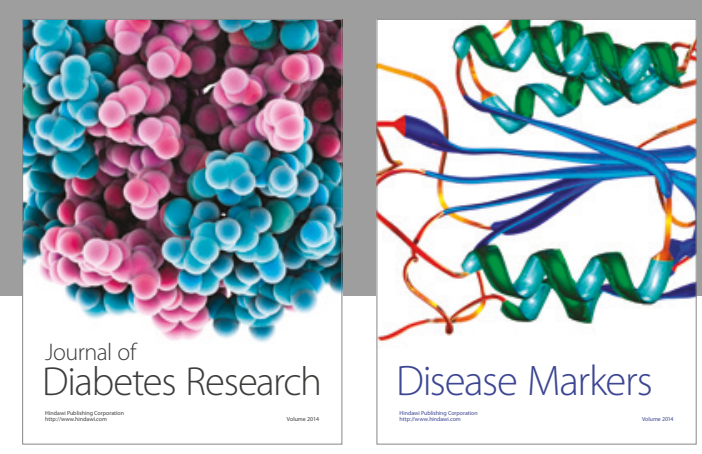

Disease Markers
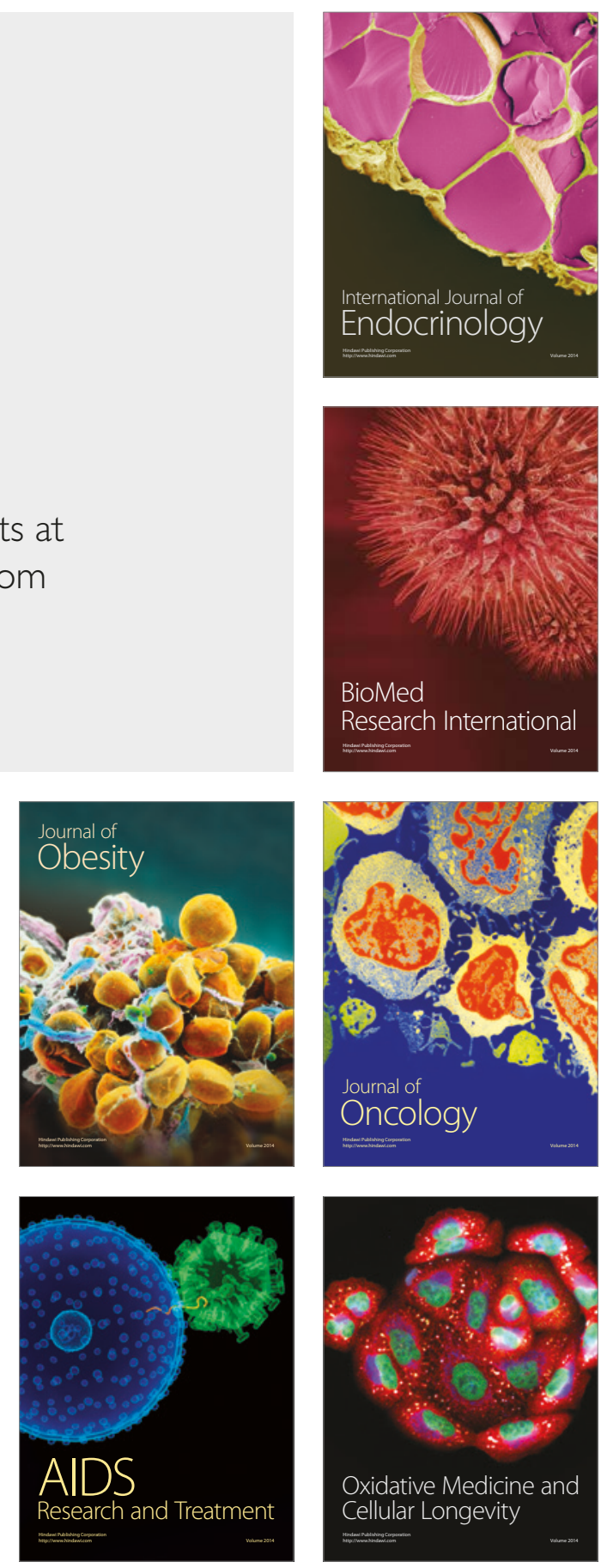